\title{
Bronne geraadpleeg
}

Allen, D 1985. Philosophy for understanding theology. London: SCM.

Armstrong, B G 1969. Calvinism and the Amyraut heresy. London.

Bainton, R H 1970. Erasmus of Christendom. London: Collins.

Baker, W J 1980. Heinrich Bullinger and the covenant: The other reformed tradition. Ohio: University Press.

Balke, W 1977. Calvijn en de Doperse radikalen. Amsterdam: Uitgeverij Ton Bolland.

Barth, K 1952. Die protestantische Theologie im 19. Jahrhundert: Ihre Vorgeschichte und ihre Geschichte. Zürich: Evangelischer Verlag.

Bauman, C 1968. Gewaltlosigkeit im Täufertum. Leiden: Brill.

Berkhof, H 1958. Christus de zin der geschiedenis. Nijkerk: Callenbach.

Boer, D 1991. Protest tegen een verkeerde wereld. Voorburg: Publivorm.

Bosman, H L e a 1987. Die Nederlandse Geloofsbelydenis - ontstaan, Skrifgebruik en gebruik, Pretoria: UNISA.

Brumfitt, J H 1972. The French Enlightenment. London: MacMillan.

Butterfield, H 1954. Christianity and history. London: G Bell \& Sons Ltd,

-1954. Christianity in European history. London: Collins.

Clasen, C P 1972. Anabaptism: A social history 1525-1618. London: Cornell University Press.

Classen, G 1981. ' $n$ Historiese blik op die Lae Lande. Pretoria: HAUM.

Cochrane, A 1966. Reformed Confessions of the 16th Century. London: SCM.

Cragg, G R 1970. The church and the age of reason. Harmondsworth: Penguin Books.

Crew, P M 1978. Calvinist preaching and iconoclasm in the Netherlands 1544-1569. Cambridge: CUP.

Dankbaar, W F 1957. Calvijn zijn weg en werk. Nijkerk: Callenbach.

De Greef, W 1989. Johannes Calvijn zijn werk en geschriften. Kampen; Uitgeverij De Groot Goudriaan.

De Jong, M J G \& Zaal, W 1960. Bilderdijk. Kampen: Kok.

De Jong, O J 1978. Nederlandsche Kerkgeschiedenis. Nijkerk: Callenbach. 
Donner, J H \& Van den Hoorn, S A s j. Acta of handelingen der nationale synode...te Dordrecht ter jare 1618 en 1619. Utrecht: Den Hertog's Uitgeverij.

Doornbos, K 1967. De Synode van Dordrecht 1618-1619 getoetst aan het recht van de kerk. Amsterdam: Buijten \& Schipperheijn.

Dreyer, P S 1974. Inleiding tot die filosofie van die geskiedenis. Pretoria: HAUM.

Duker, A C 1897-1914. Gisbertus Voetius. (4 dele.) Leiden: Brill.

Eckhof, E 1917. De Avondmaalsbrief van Corm Hoen. Den Haag.

Faulenbach, H 1973. Weg und Ziel der Erkenntnis Christi: Eine Untersuchung zur Theologie des Johannes Coccejus. Neukirchen-Vluyn: Neukirchener Verlag.

Feenstra, J G 1968. De Dordise Leerregels. Kampen: Kok.

Geyl, P 1956. Gebruik en misbruik der geschiedenis. Wolters: Groningen.

Goeters, W 1911. Die Vorbereitung des Pietismus. Leipzig: J C Hinrichs'sche Buchhandlung.

Graafland, C 1961. De zekerheid van het geloof. Wageningen: H Veenman en Zonen NV.

- 1987. Van Calvin tot Barth: Oorsprong en ontwikkeling van de leer der verkiezing in het Gereformeerd Protestantisme. 's-Gravenhage: Uitgeverij Boeken centrum BV.

- 1987. Gereformeerde scholastiek V: Die invloed van de scholastiek op de Gereformeerde orthodoxie. $T h R 30 / 1$.

Habsburg, O 1967. Karl V. Wien: Verlag Herold.

Haitjema, Th L 1962. Die Heidelbergsche Catechismus. Wageningen: H Veenman \& Zonen NV.

Hoenderdaal, G J 1960. Verklaring van Jacobus Arminius. Lochem: De Tijdstroom. Huizinga, H 1947. Erasmus. Haarlem; H D Tjeenk Willink \& Soon.

Knappert, L 1912. Geschiedenis der Nederlandsche Hervormde Kerk gedurende de agtiende en negentiende eeuw. Amsterdam: Meulenhoff.

Jacobs, P 1973. Prädestination und verantwortlichkeit bei Calvin. Darmstadt: Wissenschaftliche Buchgesellschaft.

Kantzenbach, F W 1965. Protestantisches Christentum im Zeitalter der Aufklärung. Gütersloh: Gerd Mohn.

Klooster, F H 1977. Calvin's doctrine of predestination. Grand Rapids: Baker Book House.

Knappert, L 1912. Geschiedenis der Nederlandsche Henormde Kerk gedurende de ag. tiende en negentiende eeuw. Amsterdam: Meulenhoff.

Krüger, J G 1981. Die verhouding van uitverkiesing tot bekering met spesiale verwysing na die Dordtse Leerreëls. Pretoria: NG Kerkboekhandel. 
Labuschagne, J P. Die historiese konteks van 20ste eeuse samelewingsteologie. DD-proefskrif: Universiteit van Pretoria.

Lindeboom, J 1909. Erasmus, onderzoek naar zijne theologie en zijn, godsdienstig gemoedsbestaan. Leiden: Adriani. tw not

-. 1950. Austin Friars: History of the Dutch Reformed Church in London 1550-1950. The Hague: Martinus Nijhoff.

Loonstra, B 1990. Verkiezing, versoening, verbond: Beschrijving en beoordeling van de leer van het pactum salutis in de gereformeerde theologie. 's-Gravenhage: Uitgeverij Boekencentrum.

Mabbott, J D 1973. John Locke. London: MacMillan.

Malan, C J 1981. Die Nadere Reformasie. Potchefstroom: PU vir CHO.

McNeill, John T 1967. The history and character of Calvinism. New York: Oxford University Press.

Meihuizen, H W 1961. Menno Simons. Haarlem: H D Tjeenk Willink en Zoon.

Meinhold, P 1967. Geschichte der kirchlichen Historiographie. (Twee dele.) München: Verlag Karl Alber.

Melink, A F 1954. De Wederdopers in de Noordelijke Nederlanden 1531-1544. Groningen: Wolters.

Mönnich, C W 1959. De weg en de wegen. Amsterdam: Moussault's Uitgeverij.

Muller, R A 1987. Post-reformation reformed dogmatics. Grand Rapids: Baker Book House,

Nauta, D (red) 1937. De Statenvertaling 1637-1937. Haarlem: De Erven F Bohn NV.

Nauta, D et al 1971. De synode van Emden October 1571. Kampen: Kok.

... 1978. De nationale synode van Dordrecht 1578. Amsterdam: Buijten \& Schipperheijn.

Nigg, W 1934. Die Kirchengeschichtsschreibung: Gnundzüge ihrer historischen Entwicklung. München: E H Beck'sche Verlagsbuchhandlung.

Norman, C 1972. The pursuit of the Millennium. London: Granada Publishing Ltd.

Oberholzer, J P 1986. Die Heidelbergse Kategismus. Pretoria: KITAL.

Oberman, H A 1988. De erfenis van Calvijn: Grootheid en Grenzen. Kampen: Kok.

Oliver, R P 1973. Christianity and the sunvival of the West. Cape Canaveral: Howard Allen. (Veral hfst 6, 55-74.)

Oorthuys, G 1928. Het genadeverbond en wie er toe behooren. Utrecht: J van Druten.

Oorthuys, G \& Kromsigt, P J 1933. Grondslag en wezen der kerk. Wageningen: H Veenman en Zonen.

Parker, T H L 1975. John Calvin: A biography. London: J M Dent \& Sons Ltd. 
Pont, A D 1974. Die reg van opstand by Thomas Münster. Tydsknf vir Geesteswetenskappe 14, 16-32.

-- 1981. Die historiese agtergronde van ons kerklike reg. Pretoria: HAUM.

Pont, J W 1911. Geschiedenis van het Lutheranisme in de Nederlanden tot 1618. Haarlem: De erven F Bohn.

Post, R R 1940. De Moderne Devotie. Amsterdam.

... 1957. Kerkgeschiedenis van Nederland in de Middeleeuwen. Antwerpen.

Schaff, P 1919. The Creeds of Christendom with a history and critical notes. New York: Harper \& Brothers Publishers.

Searle, G W 1974. The Counter-reformation. London: University of London Press.

Van Campen, M 1988. Leven uit Gods beloften: Een centraal thema bij Johannes Calvijn. Kampen: Uitgeverij De Groot Goudriaan.

Van Itterzon, G P \& Nauta, D (reds) 1963. Geschiedenis van de kerk. ( 9 deeltjies.) Kampen: Kok.

Van Itterzon, G P 1980. Johannes Bogeman. Amsterdam: Ton Bolland.

Van Rhijn, M 1917. Wesel Gansfort. Groningen.

-. 1920. Studiën over Wesel Gansfort en zijn tijd. Groningen.

Van Schelven, A A 1908. De Nederduitsche Vluchtelingenkerken der XVle eeuw in Engeland en Duitschland in hunne beteekenis voor de reformatie in de Nederlanden. 's-Gravenhage: Martinus Nijhoff.

Van Zyl, P 1963. Gerard Groote, ascetic and reformer, 1340-1384. Washington.

Verduin, L. The Reformers and their stepchildren. Exeter: Paternoster Press.

Wittemans, F (red) s j. Mamix van sinte Aldegonde. Brussel: Uitgeversmaatschappij Onze Tijd.

Ypey, A \& Dermout, I J 1819. Geschiedenis der Nederlandsche Henormde Kerk. (Vier dele.) Breda: W van Bergen \& Comp.

Zanchius, J 1971. Absolute predestination. Grand Rapids: Sovereign Grace Publishers. 